\title{
Predictors of seeking financial compensation following motor vehicle trauma: inception cohort with moderate to severe musculoskeletal injuries
}

\author{
Darnel Murgatroyd ${ }^{1 *}$, lan A. Harris ${ }^{2}$, Jian Sheng $\mathrm{Chen}^{3}$, Sam Adie ${ }^{4}$, Rajat Mittal ${ }^{5}$ and lan D. Cameron ${ }^{6}$
}

\begin{abstract}
Background: Compensation related factors have been repeatedly associated with poor recovery following orthopaedic trauma. There is limited research into the factors associated with seeking financial compensation. Further understanding of these factors could facilitate injury recovery by purposeful compensation scheme design. The aim of this study was to investigate the predictors of seeking financial compensation, namely making a claim and seeking legal representation, following motor vehicle related orthopaedic trauma. The study was conducted in New South Wales (NSW), Australia, in motor vehicle crash and workers' compensation schemes.
\end{abstract}

Methods: Participants were patients admitted with upper or lower extremity factures following a motor vehicle crash to two trauma hospitals. Data were collected at baseline within two weeks of injury. Participants were followed up at six months. Analysis involved: descriptive statistics for baseline characteristics; comparison of compensable and non-compensable participants with Analysis of Variance (ANOVA) and chi-squared tests; and logistic regression for predictor models.

Results: The cohort consisted of 452 participants with a mean age 40 years; 75\% male; 74\% working pre-injury; 30\% in excellent pre-injury health; 56\% sustained serious injuries with an Injury Severity Score (ISS) 9-15; 61\% had a low-middle range household income; and 35\% self-reported at fault in the crash. There was no significant difference in pre-injury/ baseline health between compensable and non-compensable participants. Follow up data was available for 301 (67\%) participants.

The significant predictor of claiming compensation in the adjusted analysis was higher body mass index (BMI) (overweight Odds Ratio [OR] 3.05, 95\% Confidence Interval [Cl] 1.63-5.68; obese OR 1.63, 95\% Cl 0.83-3.20). Participants less likely to claim were: involved in a motorcycle crash (OR 0.47, 95\% Cl 0.28-0.82); socioeconomically less disadvantaged (OR $0.37,95 \% \mathrm{Cl} 0.17-0.82$ ) or least disadvantaged (OR 0.39, 95\% Cl 0.17-0.90); at risk for short term harm (injury) due to alcohol consumption (OR 0.56, 95\% Cl 0.32-0.97); and with fair-poor pre-injury health (OR 0.30, 95\% Cl 0.09-0.94). The predictors for seeking legal representation were speaking a language other than English at home (OR 2.80, 95\% Cl 1.2-6.52) and lower household income (OR 3.63,95\% Cl 1.22-10.72). Participants less likely to seek legal representation were least socioeconomically disadvantaged (OR $0.15,95 \% \mathrm{Cl} 0.04-0.50)$.

Conclusions: Seeking financial compensation was associated with a higher pre-injury BMI rather than injury-related factors. Seeking legal representation was solely related to socio-economic factors.

Keywords: Compensation and redress, Wounds and injury, Multiple trauma

\footnotetext{
*Correspondence: dmur0062@uni.sydney.edu.au

'John Walsh Centre for Rehabilitation Research, The University of Sydney,

Kolling Institute, Sydney, NSW, Australia

Full list of author information is available at the end of the article
} 


\section{Background}

Motor vehicle related orthopaedic trauma contributes significantly to the burden of disease and injury $[1,2]$ and can occur within a compensation environment providing injured people with access to financial entitlements. Compensation related factors have been linked to poor recovery after orthopaedic trauma across different compensation systems; such factors include making a claim and legal representation [3-9]. However, these negative associations have been criticised due to the potential for reverse causality bias between compensation related factors and pre-injury and/or baseline health status $[10,11]$. Reverse causality is when the direction of cause and effect is contrary to what is presumed or is a two-way causal relationship [12]. For example, does poor health lead people to claim compensation or does claiming compensation cause poor health? As part of our analysis, we addressed the first part of this question.

To the authors' knowledge two studies have compared health status between compensable and non-compensable participants and found a difference at baseline and follow up in a trauma cohort $[3,13]$. Involvement in the compensation process and the stressfulness of having a claim has been associated with poorer mental health status following injury but a significant portion of that poorer status was present at baseline $[14,15]$. Furthermore, baseline health is a known predictor of injury recovery [4-6].

In addition, others have pointed out the need for further comparative research between and within different jurisdictions to tease apart the complex issues surrounding compensation systems including scheme design and the societal framework in which they operate $[16,17]$. Although many studies have explored the association between compensation related factors and trauma recovery, few have investigated the drivers for making a claim or seeking legal representation following motor vehicle related orthopaedic trauma.

Many compensation schemes tend to have eligibility requirements such as only being entitled to claim if they were not at fault (a fault-based scheme) or in a workrelated incident regardless of fault (a no fault scheme). These requirements dictate access to financial entitlements (benefits). Recent Australian reports show that, despite being eligible, some people choose not to make a claim. The reasons are diverse, for example: a lack of awareness of eligibility, sustaining a minor injury, prolonged injury recovery, and current and/or future employment concerns [18-20]. However, that research has been focussed on work-related injuries or Whiplash Associated Disorders (WAD).

The intricate relationship between health, psychosocial and socio-economic factors, and compensation systems has been more closely examined in the qualitative literature. Researchers have looked at the impact of the claims process, interactions between injured workers, health care providers and insurers [21-23], and financial and employment considerations [24]. Results showed having a compensation claim had largely negative influence on injury recovery. However, these relationships were mostly explored during the claims process, not prior to making a claim. Background factors (i.e. those present prior to injury) may be determinants of making a claim and/or post-injury outcomes.

Hence, the study aim was to explore the predictors for seeking financial compensation, namely making a claim and seeking legal representation, following motor vehicle related orthopaedic trauma.

\section{Methods}

\section{Study design}

Participants were recruited for this inception cohort study from two trauma hospitals (Liverpool and St George) in Sydney, NSW, Australia from November 2007 to February 2011. The selected hospitals provided a representative sample of motor vehicle related orthopaedic trauma in NSW that required inpatient hospitalisation in NSW. Participants were followed up at 6, 12 and 24 months post injury.

Eligible patients identified via a hospital trauma database of orthopaedic admissions were invited to participate. Informed consent was obtained. Inclusion criteria were: admission to hospital within 2 weeks of injury; involvement in a motor vehicle crash; age 18 years or over; and an upper or lower extremity fracture (humerus, radius, ulna, pelvis, acetabulum, femur, patella, tibia, fibula, talus, calcaneus). An English speaking family member was used to interview eligible patients from Culturally and Linguistically Diverse (CALD) backgrounds. Patients were excluded if they had: dementia or a significant pre-existing cognitive impairment preventing the ability to consent; spinal cord injury; Glasgow Coma Score (GCS) less than 12 on admission; amputation of a limb; or isolated phalangeal, carpal, metacarpal, tarsal or metatarsal fractures.

There were 32 variables measured for each participant. Calculations for the sample size of 450 were based on an allowance of 10 participants per variable [25] and accommodated a $25 \%$ loss to follow up with reference to similar published research $[8,26]$.

At six, 12 and 24 months after injury follow up questionnaires were posted to participants. By 3 weeks, if there was no response participants were contacted up to six times by telephone. Questionnaires could be completed by telephone or by mail. Participants were removed from the study if non-contactable or they declined to participate. Additional information about the study methodology is published in two separate papers 
investigating injury recovery and return to work in the same cohort [27, 28].

Baseline data were collected in hospital within 2 weeks post injury by written questionnaire. Demographic data including date of birth, age, gender, and injury related information were obtained from hospital records and a trauma database. Selected study factors were based on relevant research and referred to the aims and objectives of the study $[6,7,29,30]$.

\section{Setting}

In NSW at the time of the study, the Motor Accidents Authority (MAA) was the government insurance regulator of the CTP personal injury scheme, and is a privately underwritten modified common law scheme. WorkCover was the government insurance regulator of the WC scheme, and is a publically underwritten statutory benefit scheme where private insurers manage claims on behalf of WorkCover [31, 32]. In 2015, the scheme regulators amalgamated and formed the State Insurance Regulatory Authority (SIRA).

All motor vehicles travelling on public roads must be registered. To make a CTP claim a motor vehicle must also be registered and the claim is made against the driver at fault. From April 2010, anyone injured in a motor vehicle crash (regardless of fault) can access limited entitlements, that is: medical expenses and lost wages up to AUD (Australian Dollar) \$5000. Before 2012, to make a WC claim a motor vehicle crash must have occurred during travel between place of employment and home, and/or any work-related place, and a person injured (regardless of fault) [31, 32].

For both schemes, a claim must be lodged within six months of injury and insurers have 3 months to determine final liability (accept/deny the claim). Provisional liability facilitates access to treatment by earlier payment of medical expenses and for WC weekly wage benefits. In WC, within $48 \mathrm{~h}$ insurers must be informed of an injury [32]. Entitlements include past and future losses: for example, medical expenses, loss of income, and pain and suffering/impairment. In both schemes, payments for medical expenses are made as incurred. In CTP, loss of income (including past and future), future medical expenses, and permanent impairment are paid as a lump sum at claim settlement. In WC, loss of income is paid weekly and can be lifetime depending on the level of impairment. Future medical expenses can be lifetime, and permanent impairment is paid as a lump sum. In addition, legal representation can also be sought at any time for either scheme. [31, 32]

\section{Injury related study factors}

The Abbreviated Injury Scale (AIS) (1990 Revision, Update 98) was used to code all injuries [33]. The Injury
Severity Score (ISS) and New Injury Severity Score (NISS) were calculated as measures of injury severity; these are considered indicators of potential mortality [34] and are the sum of the squares of the three highest AIS scores from different body regions (ISS) regardless of body region (NISS). The AIS ranks injuries to particular body regions on a scale from one to six (six is not survivable). Injuries were classified as minor-moderate (1-8), serious (9-15) or severe-critical (16-75) based on ISS/NISS scores [35].

\section{Socio-demographic study factors}

Socio-demographic factors included age, gender, marital status, occupation, and education. Occupation was measured using the Australian Standard Classification of Occupations (ASCO), classifications were divided by skill level (e.g. managers/professionals, tradespersons, intermediate clerical and elementary related) $[28,36]$. Current work status (yes/no) was asked with additional variables for full/modified duties (e.g. lifting restrictions, reduced hours) and full-time (usually working at least $35 \mathrm{~h}$ per week) or part-time (usually working one hour to $35 \mathrm{~h}$ per week) [37].

Household income was measured exclusive and inclusive of household structure to cater for any differences in income distribution. To calculate an adjusted income (inclusive of household structure), household income was divided by the sum of points, 1 for the first person aged $\geq 15$ years, 0.5 for each additional person aged $\geq 15$ years, and 0.3 for each person aged $<15$ years $[38,39]$.

The Index of Relative Socioeconomic Disadvantage (IRSD) summarises economic and social conditions within a particular area/postcode such as employment, fluency in English and household size [38]. The lowest score is indicative of greatest or most socioeconomic disadvantage and the highest score indicates least disadvantage. It can be used as a continuous variable or divided into quintiles.

\section{Health related study factors}

Different health conditions measured as indicators of general health status at baseline were chronic illnesses asthma, cancer, heart and circulatory conditions, diabetes, arthritis, osteoporosis, mental and behavioural problems, and neck and back problems/disorder/pain. The National Health Priority Areas initiative list these conditions as imposing high social and financial costs on Australian society) [40]. The classification was based on the Australian Bureau of Statistics (ABS) Health Survey which defines a long term condition as one which the patient currently has, and which has lasted or they expect to last for 6 months or more [39-41]. Body Mass Index (BMI) was calculated from the participant's selfreported weight and height. 
Other factors measured in accordance with the ABS Health Survey included: recent injuries (other than the motor vehicle crash) in the last 4 weeks that required medical intervention or were associated with a decrease in usual activities; medication use in the last 2 weeks for asthma, arthritis, osteoporosis, heart or circulatory conditions, diabetes, high sugar levels, mental wellbeing; and smoker status [39].

In previous research, associations were found between poor recovery and poor expectations for return to usual activities and work [29, 42-44]. There were few validated measures for self-efficacy and other similar constructs, therefore, two applicable measures from a large Canadian study of soft tissue injuries were used [43]. These were 'do you expect to return to work (yes/no)' and 'when do you expect to return to usual activities' (number of days).

A validated scale measured alcohol consumption with the first three questions of the Alcohol Use Disorders Identification Test: Self-Report Version (AUDIT-C) [45, 46]. The word 'standard' and 'in the past year' were added. Alcohol quantity was based on an Australian standard drink [47, 48]. The AUDIT-C questions measure number and frequency of drinking. The National Health and Medical Research Council (NHMRC) levels were used to assess risk of long term harm (alcohol related disease) and/or short term harm (alcohol related injury) due to alcohol consumption [47]. The risk levels for long term harm were low risk, risky, and high risk based on the number of standard drinks/week consumed over the past year. The risk level for short term harm was if $\geq 6$ standard drinks were consumed on one occasion, on one day over the past year.

Because these measures did not match the AUDIT-C categories, to compare results an algorithm was calculated from the Bettering the Evaluation of Care and Health (BEACH) Survey, (Professor K Conigrave, personal communication March 19, 2007). Categories for other study factors are explained in the tables and our other published research from the same cohort that investigated predictors of injury recovery and return to work. $[27,28]$

\section{Compensation related measures}

Most compensation related factors were not recorded at baseline because the questions were unanswerable (within 2 weeks of injury). At 6 months post injury the questions asked were: claim made (yes/no), claim type (Compulsory Third Party [CTP]/Workers Compensation [WC]/other), claim accepted (yes/no/don't know), and legal representation obtained (yes/no). Claim made 'yes' was defined as making a personal injury claim of any type (CTP, WC or other) to access entitlements, which included a CTP Accident Notification Form (ANF) for expenses $<$ AUD $\$ 5000$ within 28 days of injury. Selfreported fault of the driver was measured at baseline (i.e. whether the driver considered themselves to have caused the crash). Pedestrians and passengers were considered not at fault (at baseline) because road rules dictate that vehicles must give way to pedestrians. However, both have a responsibility for their own safety and where they fail to take care, rules of apportionment under contributory negligence apply, that is: the insurer believes that the person contributed to the crash and/or their injuries (e.g. not wearing a seatbelt or crossing the road at a red traffic light can result in reduced financial entitlements at settlement [49].

\section{Data analysis}

Descriptive statistics were used to summarise baseline characteristics of the participants by claim status (i.e. made a claim Yes/No) at 6 months. The differences in the baseline characteristics between those that claimed compensation and those that did not were compared using Analysis of Variance (ANOVA) tests for continuous variables and chi-squared tests for categorical variables. The variables met the assumptions of independence, homoscedasticity and normality. Chi-squared tests were also undertaken to determine relationships between claim type and legal representation as well as claim type and claim acceptance. Logistic regression models were employed to determine predictors of claiming compensation and legal representation at six months. All potential predictor variables were considered for the final predictive models. We included variables with a $p$-value of $<0.20$ in univariate analyses and retained only variables with a $p$-value of $\leq 0.10$ in the final models. Variables for the final model were selected using a backward elimination technique based on changes in likelihood ratios. The Spearman's RankOrder Correlation Coefficient and the Variance Inflation Factor (VIF) tests were performed to check for multicollinearity between variables in the model. The C-statistic (equivalent to the area under the Receiver Operating Characteristic curve) was used as an indication of the predictive accuracy of the final models. To assess the impact of eligibility factors, sensitivity analysis was conducted using only those participants that were eligible $(n=180)$. All data analysis was performed using SPSS statistical software version 21 (SPSS Inc, USA).

\section{Results}

\section{Baseline characteristics}

There were 840 eligible participants admitted to both hospitals (November 2007 - February 2011), 491 were screened with 452 (92\%) consenting to participate. Due to limited resources, 349 eligible participants were not screened. Additional analysis of those eligible but not 
screened was not possible due to lack of patient consent ethical considerations. Potential participants were likely to have been missed at random. There were 31 refusals and eight who were discharged and unable to be contacted. Reasons for refusals were: not interested (10); language difficulties (5); and already involved in another study (1). The remaining 15 gave no reason. Further results about the cohort's baseline characteristics, injury recovery and return to work outcomes are published in two additional papers $[27,28]$.

The baseline characteristics are described from a total of 452 unless otherwise stated. The mean age of participants in the study was 40 years (17.1 SD) with a range of 18-87 years. The majority 253 (56\%) ISS and 189 (42\%) NISS sustained serious injuries with ISS/NISS of 9-15; 124 (27\%) ISS and 93 (21\%) NISS sustained minor to moderate injuries (ISS/NISS) of 1-8; and the reminder 75 (17\%) ISS and 170 (38\%) NISS sustained severe to critical injuries (ISS/NISS) of 16-75. Male participants made up the majority at $332(75 \%)$. More participants $279(62 \%)$ were in the IRSD middle and lower two quintiles with corresponding middle and lower household income brackets. Seventeen percent (75) had obtained a bachelor degree or above.

At the time of injury 334/450 (74\%) participants were working, mostly full time 273/330 (83\%) and full duties 321/334 (96\%). Expectations to return to work were high 299/333 (90\%) as was job satisfaction 320/334 (96\%). While only $267 / 424$ (63\%) participants expected to return to usual activities in $\leq 90$ days. Thirty five percent (157/451) considered themselves at fault in the crash and 410 (91\%) crashes occurred on a public road.

Excellent pre-injury health was perceived by 137 (30\%), while 31 (7\%) considered it fair to poor. Regarding other health factors, 157 (35\%) reported one or more chronic illnesses, $268 / 448$ (60\%) were overweight or obese, $157(27 \%)$ took medication within the last 2 weeks, and 125/450 (28\%) were current smokers. There was a higher risk of short term harm for 254 (56\%) due to alcohol consumption, that is: injury due to alcohol consumption, but a low risk of long term harm for 420/ 451 (93\%), that is: disease due to alcohol consumption (data not shown).

\section{Compensation and participant status}

In line with the study aims, participants were analysed by their compensation status (i.e. claim made or no claim made regardless of claim acceptance). This included all variables measured at baseline. There were 301 (67\%) participants who completed the 6 month questionnaire, of those 294 responded to the compensation related questions and 61\% (179/294) made a claim, of those 125/179 (70\%) sought legal representation. The characteristics of each group are illustrated in an earlier publication [27], but briefly the results showed that there were significant differences between the compensable and non-compensable groups. Notably, most of those eligible to claim under NSW legislation made a claim: $82 \%$ of participants who self-reported not at fault and 95\% who had a crash on a public road. There were no significant differences found in pre-injury or baseline general health status between the two groups, although the measures pertained mostly to physical health.

The significant differences at follow up between responders and non-responders have been reported previously [27]. In summary, non-responders were young and pre-injury, they were more likely to be single, have smoked, not to have worked and/or had lower occupational skill levels. For all other variables there was no significant difference $(p>0.05)$ between responders and non-responders (data not shown).

Within the compensable cohort $(n=179)$ that is, those who made a claim, rates of claim acceptance and legal representation at 6 months were investigated. These results are shown in Table 1. A CTP claim was made by 117 participants, with $80 \%$ being legally represented at 6 months compared to $48 \%$ of the $54 \mathrm{WC}$ claimants. Only $55 \%$ of CTP claimants knew their claim was accepted compared to $82 \%$ of WC claimants. There were eight other claims (i.e. not CTP or WC). These differences were significant $(p<0.001)$ across the three groups (i.e. CTP, WC and other).

\section{Predictors of making a claim}

In the unadjusted analysis the most significant predictors of making a claim reflected greater eligibility to claim such that participants who self-reported at fault were much less likely to claim (OR $0.14,95 \%$ CI $0.08-0.23$,

Table 1 Relationships ${ }^{\#}$ between claim type and legal representation ${ }^{\mathrm{a}}$ and claim acceptance among 179 participants who made a claim within first 6 months

\begin{tabular}{llll}
\hline \multicolumn{4}{c}{ Claim type at 6 months } \\
\cline { 2 - 4 } & $\begin{array}{l}\text { Compulsory Third } \\
\text { Party No. (\%) }\end{array}$ & $\begin{array}{l}\text { Workers Compensation } \\
\text { No. (\%) }\end{array}$ & $\begin{array}{l}\text { Other }^{\text {b }} \\
\text { No. (\%) }\end{array}$ \\
\hline $\begin{array}{l}\text { Legal representation at } 6 \text { months } \\
\text { Yes }\end{array}$ & $93(79.5)$ & $26(48.1)$ & $6(75.0)$ \\
No & $24(20.5)$ & $28(51.9)$ & $2(25.0)$ \\
Claim acceptance at 6 months & & \\
Yes & $64(54.7)$ & $44(81.5)$ & $2(25.0)$ \\
No & $10(8.5)$ & $0(0)$ & $2(25.0)$ \\
Don't know & $43(36.8)$ & $10(18.5)$ & $4(50.0)$ \\
\hline
\end{tabular}

${ }^{a}$ Not all participants who sought legal representation made a claim $(n=3)$ ${ }^{\mathrm{b}}$ (medical negligence $=1$, Australian Defence Force $(A D F)=1$, Department of Veteran Affairs (DVA) $=1$, income protection insurance $=1$, civil action $=1$, not stated $=3$ )

"Relationships were considered significant for any association with $p$ value $<0.05$ 
Table 2 Predictors for making a claim at 6 months ( $n=294,179$ [61\%] made a claim)

\begin{tabular}{|c|c|c|c|c|}
\hline Variable $^{a}$ & Unadjusted OR (95\% Cl) & $P$ & Adjusted $^{\mathrm{b}} \mathrm{OR}(95 \% \mathrm{Cl})$ & $P$ \\
\hline Body Mass Index $(\mathrm{BMI})^{\mathrm{e}}\left(\mathrm{kg} / \mathrm{m}^{2}\right)$ & & 0.07 & & 0.005 \\
\hline$<18.50$ (underweight) & $1.28(0.27,6.02)$ & & $0.87(0.17,4.40)$ & \\
\hline 18.50-24.99 (normal) & 1.00 & & 1.00 & \\
\hline$\geq 25.00$ (overweight) & $2.14(1.22,3.76)$ & & $3.05(1.63,5.68)$ & \\
\hline$\geq 30.00$ (obese) & $1.47(0.80,2.71)$ & & $1.63(0.83,3.20)$ & \\
\hline Vehicle type & & 0.02 & & 0.03 \\
\hline Motor vehicle & 1.00 & & 1.00 & \\
\hline Motorcycle & $0.49(0.30,0.80)$ & & $0.47(0.28,0.82)$ & \\
\hline Bicycle & $0.66(0.20,2.16)$ & & $0.91(0.26,3.21)$ & \\
\hline Index of Relative Socioeconomic Disadvantage & & 0.09 & & 0.04 \\
\hline Most disadvantaged (quintile 1) & $0.87(0.42,1.81)$ & & $0.70(0.32,1.55)$ & \\
\hline More disadvantaged (quintile 2) & $1.30(0.44,3.89)$ & & $1.13(0.35,3.67)$ & \\
\hline Average (quintile 3) & 1.00 & & 1.00 & \\
\hline Less disadvantaged (quintile 4) & $0.45(0.22,0.93)$ & & $0.37(0.17,0.82)$ & \\
\hline Least disadvantaged (quintile 5) & $0.62(0.29,1.33)$ & & $0.39(0.17,0.90)$ & \\
\hline Male & $0.56(0.32,0.95)$ & 0.03 & & \\
\hline Education skill level $^{c}$ & & 0.11 & & \\
\hline Bachelor degree and above & 1.00 & & & \\
\hline Certificate and advanced diploma & $0.59(0.30,1.16)$ & & & \\
\hline Secondary education & $0.73(0.37,1.47)$ & & & \\
\hline Pre-primary and primary education & $5.19(0.62,43.6)$ & & & \\
\hline Work hours before injury & & 0.07 & & \\
\hline Fulltime & 1.00 & & & \\
\hline Part time & $2.44(1.13,5.25)$ & & & \\
\hline Didn't work & $1.28(0.72,2.27)$ & & & \\
\hline Language other than English (yes) & $1.75(1.05,2.89)$ & 0.03 & & \\
\hline Risk of short term harm due to alcohol consumption (yes) & $0.58(0.36,0.94)$ & 0.03 & $0.56(0.32,0.97)$ & 0.04 \\
\hline Pre-morbid neck pain in last 6 months (yes) & $0.41(0.14,1.18)$ & 0.10 & & \\
\hline Self-assessed pre-injury health status ${ }^{d}$ & & 0.08 & & 0.05 \\
\hline Excellent & 1.00 & & 1.00 & \\
\hline Very good & $1.12(0.63,1.98)$ & & $1.45(0.77,2.74)$ & \\
\hline Good & $1.13(0.59,2.14)$ & & $1.16(0.58,2.34)$ & \\
\hline Fair-Poor & $0.29(0.10,0.84)$ & & $0.30(0.09,0.94)$ & \\
\hline
\end{tabular}

${ }^{\mathrm{a}}$ All variables with $p$ value $<0.20$ (unadjusted) and $p$ value $\leq 0.10$ (adjusted) were included in the data analysis

${ }^{\mathrm{b}}$ Adjusted for other variables in the column

'The measure for education is from the Australian Standard Classification of Education (ASCED), Cat. No. 1272.0, Australian Bureau of Statistics 2001

${ }^{d}$ Self-assessed pre-injury health status is based on Question 1 from the Short Form 36, version 2, (SF36v2)

e $\mathrm{BMI}$ classification is from the Global Database on Body Mass Index, World Health Organisation

$p<0.001)$, and participants who were involved in a crash on a public road were more likely to claim (OR 3.74, $95 \%$ CI 1.63-8.59, $p=0.002$ ). For our study, we were interested in factors other than eligibility and the final model did not include these two variables; these results are shown in Table 2.

The sensitivity analysis that investigated the impact of those eligibility variables (self-reported not at fault and crash on a public road) showed that BMI was the only significant predictor in the smaller eligible only model. All other variables were not significant. The effect sizes of the non-significant variables were all in the same direction with similar (but reduced) magnitudes, when compared to the full group. The overall performance of the models in two groups was similar with concordance index of 0.71 and 0.72 for the full model and smaller 
Table 3 Predictors for seeking legal representation at 6 months ( $n=179,125$ [70\%] sought legal representation)

\begin{tabular}{|c|c|c|c|c|}
\hline Variable $^{a}$ & Unadjusted OR (95\% Cl) & $P$ & Adjusted $^{\mathrm{b}}$ OR $(95 \% \mathrm{Cl})$ & $P$ \\
\hline Language other than English (yes) & $2.47(1.23,5.00)$ & 0.01 & $2.80(1.2,6.52)$ & 0.02 \\
\hline Index of Relative Socioeconomic Disadvantage & & 0.11 & & 0.02 \\
\hline Most disadvantaged (quintile 1) & $0.45(0.16,1.28)$ & & $0.35(0.11,1.07)$ & \\
\hline More disadvantaged (quintile 2) & $0.63(0.15,2.61)$ & & $0.98(0.16,5.86)$ & \\
\hline Average (quintile 3) & 1.00 & & 1.00 & \\
\hline Less disadvantaged (quintile 4) & $0.40(0.13,1.23)$ & & $0.50(0.16,1.60)$ & \\
\hline Least disadvantaged (quintile 5) & $0.23(0.08,0.69)$ & & $0.15(0.04,0.50)$ & \\
\hline Male & $0.47(0.23,0.99)$ & 0.05 & & \\
\hline Marital status & & 0.07 & & \\
\hline Single & 1.00 & & & \\
\hline Married/de facto & $0.68(0.34,1.37)$ & & & \\
\hline Divorced/widowed/separated & $6.48(0.80,52.7)$ & & & \\
\hline Work status before injury (working) & $0.35(0.14,0.89)$ & 0.03 & & \\
\hline Recovery expectations for work (yes) & $0.29(0.06,1.33)$ & 0.11 & & \\
\hline $\begin{array}{l}\text { Total yearly household income (before tax, AUD) } \\
\text { excluding number of people in household }{ }^{ \pm}\end{array}$ & & 0.04 & & 0.045 \\
\hline$\leq \$ 39,999$ & $3.49(1.29,9.43)$ & & $3.63(1.22,10.72)$ & \\
\hline$\$ 40,000-\$ 79,999$ & $1.10(0.53,2.32)$ & & $0.98(0.44,2.17)$ & \\
\hline$\geq \$ 80,000$ & 1.00 & & 1.00 & \\
\hline Alcohol use in the past year & & 0.05 & & \\
\hline Never & $4.40(1.15,16.9)$ & & & \\
\hline$\leq 1 /$ month & $0.80(0.28,2.28)$ & & & \\
\hline 2-4 times/month & $1.50(0.50,4.51)$ & & & \\
\hline 2-3 times/week & $0.78(0.26,2.37)$ & & & \\
\hline$\geq 4$ times/week & 1.00 & & & \\
\hline Pre-morbid neck pain in last 6 months (yes) & $0.20(0.04,1.14)$ & 0.07 & & \\
\hline Post-morbid neck pain (yes) & $2.21(0.91,5.40)$ & 0.08 & & \\
\hline
\end{tabular}

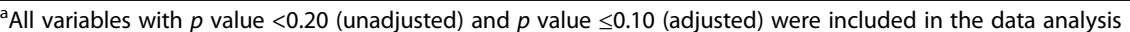

${ }^{\mathrm{b}}$ Adjusted for other variables in the column

${ }^{ \pm}$Categories of income are from the Household, Income and Labour Dynamics in Australia (HILDA) Survey Wave 6 Household Questionnaire

eligible model, respectively. The significant predictor of claiming compensation in the adjusted analysis was BMI. Obese or overweight participants were more likely to make a claim than those with normal or low BMI. Participants involved in a motorcycle crash and those at risk for short term harm (injury) due to alcohol consumption were less likely to make a claim than those who were not at risk. Those who were socioeconomically less disadvantaged and least disadvantaged were less likely to claim compared with those of average disadvantage and those with fairpoor health compared to those with excellent health were also less likely to claim. The C-statistic for the multivariable logistic regression model was 0.71 indicating that the predictive value of the model was acceptable. Values of 0.8-0.9 are considered excellent but higher values are rare [50].

\section{Predictors of seeking legal representation}

As previously described, the final model did not include the two variables pertaining to eligibility. The significant predictors of self-reported fault (OR $0.08,95 \%$ CI $0.03-0.19, p<$ 0.001 ) and crash on a public road (OR 9.16, 95\% CI 1.84-45.7, $p=0.007$ ) were removed from the analysis.

Participants who spoke a language other than English at home were more likely to seek legal representation, and those participants with a household income of $\leq$ AUD\$39,999 were more likely to seek legal representation compared to participants with higher household income. Participants who were least socioeconomically disadvantaged were less likely to seek legal representation compared to participants with average disadvantage, this relationship was not linear. These results are displayed in Table 3. The C-statistic for the multivariable logistic regression model was 0.77 . 
To check for multicollinearity between the variables in the models, correlations and VIF were tested. The correlations found were small, that is: $r_{s}<0.4$ and unlikely to cause any multicollinearity problems. This was confirmed with multicollinearity diagnostic testing using VIF with results showing VIFs $\leq 2$ for all the variables. A VIF of greater than 5 or 10 usually indicates a multicollinearity problem.

\section{Discussion}

In summary, the significant predictor of making a claim was being overweight or obese. Motorcycle crash, risk of short term harm due to alcohol consumption and poorer pre-injury health were associated with a decreased likelihood of making a claim. Amongst compensable participants, the predictors of seeking legal representation were largely related to socio-economic factors. Lastly, the differences between compensable and non-compensable participants were not related to physical pre-existing/baseline health status measures.

\section{Compensation status}

It has been suggested that people with poorer health are more likely to claim than those in good health and that pre-injury/baseline health accounts for a poorer recovery not 'exposure' to compensation $[10,11]$. We found that the differences between those 'exposed' (i.e. made a claim) and those 'unexposed' were not related to certain health measures. Bias from reverse causality was not detected in this cohort [12]. However, these results should be interpreted with caution due to the limited psychological variables measured.

The timeframes for claim acceptance reflect scheme design - WC is no-fault, CTP is fault-based, the latter can delay liability determinations. Likewise, explanations for high legal representation include liability issues, access to financial entitlements and/or the complexity of negotiating the claims process as reported previously $[15,23]$.

\section{Predictors of making a claim and seeking legal representation}

Eligibility contributes to propensity to claim, which is as expected. However, injury severity (ISS/NISS) was not a predictor, which is unexpected given the moderate to severe injuries sustained by participants. It has been shown that those with minor injuries are far less likely to claim due to the inconvenience and effort required particularly if the injury does not cause any significant impact (e.g. minimal pain or loss of function) [18, 19]. For other factors, higher BMI has been associated with poorer physical and mental health, long term disability, and chronic pain [51-53]. In Australia, where almost $63 \%$ of adults are overweight or obese, obesity is a national health priority area and a significant public health problem [40]. Overweight or obese people could be faced with a prolonged recovery and therefore, more likely to claim. There is evidence linking obesity to increased WC claim rates and costs, and additional sick leave across numerous jurisdictions particularly for upper and lower limb injuries [54-56]. It follows that people with a higher BMI may be more likely to experience greater levels of disability and people with greater disability are more likely to make a claim.

For those less likely to claim, motorcyclists are more likely to be involved in single vehicle crashes [57]. In these crashes there is no one to claim against [31]. In addition, speeding and alcohol are stronger contributors to single vehicle crashes, which could result in traffic and/or criminal violations [57]. In NSW, a police report is required to make a claim and motorcyclists could be less likely to approach police under these circumstances $[58,59]$. These are plausible reasons for the low claim rate in motorcyclists.

Similarly, short term harm due to greater alcohol consumption increases the risk of alcohol-related injury [60]. The most common cause of death due to intoxication is a road traffic crash [61], and alcohol consumption is linked to numerous medical conditions, which along with preinjury fair-poor health could be associated with being more or most disadvantaged and/or not understanding how to claim. This last comment should be interpreted cautiously due to small numbers in this group (31/452, $7 \%$ ). In addition, those who are socioeconomically less or least disadvantaged are more likely to have higher levels of education and be employed in professional and/or associated professional jobs (e.g. managers and administrators), and less likely to have co-morbidities. This is likely to reduce their need to claim for economic and other losses such as medical expenses [62].

Besides eligibility, a person's decision whether or not to make a claim can also be influenced by other factors. These include a perception their injury is too minor, concerns about current or future employment options, and/or a lack of knowledge about eligibility to claim $[18,19]$. Our study population sustained moderate to severe, not minor injuries, so this is unlikely to have been a factor. Concerns about current or future employment options and a lack of knowledge about eligibility to claim are possible but they were not measured in this study.

The sensitivity analysis for only those eligible to make a claim, showed that higher BMI was the one significant predictor in this smaller model, but the reduced effect sizes of all the other variables (i.e. those that were significant in the larger model) could indicate that these variables may be less relevant when restricted to the eligible population and/or a larger sample size is needed in future research. 
The predictors of legal representation were speaking a language other than English at home and a low household income. These factors are commonly associated with health inequities (e.g. increased illness and disability, poor access to health services, and poor health literacy) $[62,63]$. These inequities could lead to increased legal representation due to the complexity of managing a claim (e.g. understanding legal terminology to access financial entitlements in the circumstances surrounding the crash and fault status) and/or accessing health care services via a third party payer (the insurer) [15, 23]. Alternatively, people who are less or least socioeconomically disadvantaged may not require legal assistance to access financial entitlements because of greater competency navigating the claims process particularly if work capacity is not affected.

Moreover, qualitative research shows people feel they require legal representation to assist with adversarial claims processes, accessing reasonable entitlements, perceived illegitimacy of injury, and system disorganisation (e.g. communication and administrative deficits) $[21,23,24]$. It is feasible these factors would be challenging to people with limited English proficiency and those from lower socio-economic backgrounds particularly in the presence of physical or psychological limitations.

\section{Strengths and limitations}

Our prospective study was a trauma cohort of moderate to severe injuries involving upper and lower limb fractures. We used validated and standardised measures. Participants were predominantly male, from lower socioeconomic backgrounds with a household income below AUD $\$ 80,000$. Although reflective of a more severe trauma population, they may not be representative of all CTP and WC claimants. The issues surrounding eligibility to claim are complex, dependent on scheme design and involve a myriad of legal interpretations.

It would have been beneficial to measure self-reported fault by including the constructs of blame, perceived injustice and/or attributions of responsibility [64, 65]. Recent research has shown that these factors are significant predictors of poorer health outcomes [5, 64, 65]. Fault (i.e. the driver caused the crash) is not the same as blame (i.e. blaming someone or something for the injury) $[64,65]$. For example, a driver may have 'caused' the crash, but blame his/her passenger for distracting them or poor road conditions. Blame or perceived injustice do not necessarily mean access to compensation. Our singular measure did not encompass these constructs.

Further, the collection of baseline psychological variables would have been useful (e.g. depression, pain catastrophising and/or anxiety). Poor baseline mental health and stressfulness has been associated with poor recovery in a compensable setting; which could impact on making a claim and seeking legal representation [14, 15]. Other limitations were recruitment of participants solely from hospital and moderate loss to follow-up (32\%).

Lastly, we did not include any indices of social support. There is growing awareness of the importance of social support to aid injury recovery and return to work [66]. There are a number of validated measures of workplace and family support and future research would benefit from their inclusion $[67,68]$.

\section{Future research and policy implications}

The predictors of making a claim illustrate the problems associated with a higher BMI and how this extends into the compensable arena. However, scheme regulators and insurers are limited in their capacity to address this significant societal issue. Conversely, those less likely to claim may benefit from access to health care services and financial entitlements and, if socioeconomically less or least disadvantaged, may have no need to claim for these items. The predictors of seeking legal representation provide insight into the importance of socio-economic and language factors.

Given the limited research, these factors need to be explored in different populations with alternative compensation systems to determine whether the findings are replicable. The presence of reverse causality bias should be routinely investigated if compensation related factors are potential confounders.

For policy makers there is an opportunity to conduct risk assessments, identify those likely to struggle post injury, and attempt to mitigate that risk with proactive health interventions and claims management. In addition, extra assistance for claimants from CALD and lower socio-economic backgrounds may alleviate some of the pressure to seek external advice. For example: face-face meetings conducted in an appropriate language; a streamlined claims process; and/or early payments for treatment and financial hardship. Conversely, those socioeconomically less or least disadvantaged may benefit from minimal insurer intervention.

Finally, the generalisability of our results could be affected by the diverse and complex socio-political environment of compensation schemes. For example, NSW has a predominantly fault-based modified common law CTP scheme; whereas other Australian states have purely common law or no-fault CTP schemes. Internationally, compensation schemes are based on mechanism of injury and/or type of disability, and/or governing legislation to access financial entitlements. Notwithstanding that, themes from qualitative research appear to be consistent across jurisdictions and countries [21, 22]. Further, increased BMI has been associated with greater absenteeism, healthcare costs and claim 
rates across numerous jurisdictions, albeit in larger cohorts $[55,56]$.

\section{Conclusion}

Seeking financial compensation was associated with a higher pre-injury BMI rather than injury-related factors. Seeking legal representation was solely related to socio-economic factors. Evidence to date suggests these relationships are complex, population specific and dependent on scheme design.

\begin{abstract}
Abbreviations
ABS: Australian Bureau of Statistics; ADF: Australian Defence Force;

AIS: Abbreviated injury scale; ANF: Accident notification form; ANOVA: Analysis of variance; ASCED: Australian Standard Classification of Education; ASCO: Australian Standard Classification of Occupations; AUD: Australian dollar; AUDIT-C: Alcohol use disorders identification test: self-report version; BEACH: Bettering the evaluation of care and health; BMI: Body mass index; CALD: Culturally and linguistically diverse; Cl: Confidence interval; CTP: Compulsory third party; DVA: Department of Veteran Affairs; GCS: Glasgow coma scale; HILDA: Household, income and labour dynamics in Australia; IRSD: Index of relative socioeconomic disadvantage; ISS: Injury severity score; MAA: Motor accidents authority; NHMRC: National Health and Medical Research Council; NISS: New injury severity score; NSW: New South Wales; OR: Odds ratio; PCS: Physical component score; SD: Standard deviation; SF36v2: Short form-36 version 2.0; SIRA: State insurance regulatory authority; VIF: Variance inflation factor; WC: Workers compensation
\end{abstract}

\section{Acknowledgements}

We would like to thank Dr Yvonne Tran for her assistance with the additional statistical analysis, and Ms Shirley Cross for their assistance with recruitment and data collection.

\section{Funding}

No funding was received for this study. Professor lan Cameron's salary is supported by an Australian National Health and Medical Research Council Practitioner Fellowship.

\section{Availability of data and materials}

All data and information about materials are in the paper and/or available from the first author.

\section{Authors' contributions}

DM was involved in the study conception and design, data acquisition, analysis, interpretation, and drafting the manuscript. $\mathrm{IH}$ and $\mathrm{IC}$ were involved in study conception and design; data acquisition, analysis and interpretation, and editing the manuscript. JSC conducted the statistical analysis and provided data interpretation (deceased 22 October 2014). SA and RM were involved in data collection, critical review and analysis of results, and editing the manuscript. All authors read and approved the final manuscript.

\section{Authors' information}

Not applicable.

\section{Competing interests}

The authors declare that they have no competing interests.

\section{Consent for publication}

Not applicable.

\section{Ethics approval and consent to participate}

The study was approved by the governing human research ethics committees (South Western Sydney Local Health District, South Eastern Sydney Local Health District, and The University of Sydney).

\section{Publisher's Note}

Springer Nature remains neutral with regard to jurisdictional claims in published maps and institutional affiliations.

\section{Author details}

John Walsh Centre for Rehabilitation Research, The University of Sydney, Kolling Institute, Sydney, NSW, Australia. ${ }^{2}$ Orthopaedic Surgery, Ingham Institute for Applied Medical Research, South Western Sydney Clinical School, UNSW, Sydney, NSW, Australia. ${ }^{3}$ Department of Rheumatology, Royal North Shore Hospital, St Leonards, NSW, Australia. ${ }^{4}$ South West Sydney Clinical School, UNSW, Sydney, NSW, Australia. ${ }^{5}$ Ingham Institute for Applied Medical Research, South Western Sydney Clinical School, UNSW, Sydney, NSW, Australia. ${ }^{6}$ Rehabilitation Medicine, John Walsh Centre for Rehabilitation Research, The University of Sydney, Kolling Institute, Sydney, NSW, Australia.

Received: 5 October 2016 Accepted: 25 April 2017

Published online: 02 May 2017

\section{References}

1. World Health Organization. Global health risks: mortality and burden of disease attributable to selected major risks. Geneva: World Health Organization; 2009. Available from: http://www.who.int/healthinfo/global_burden_disease/ GlobalHealthRisks_report_full.pdf. Accessed 1 March 2017.

2. Murray CJ, Vos T, Lozano R, Naghavi M, Flaxman AD, Michaud C, et al. Disability-adjusted life years (DALYs) for 291 diseases and injuries in 21 regions, 1990-2010: a systematic analysis for the Global Burden of Disease Study 2010. [Erratum appears in Lancet. 2013 Feb 23;381(9867):628 Note: AlMazroa, Mohammad A [added]; Memish, Ziad A [added]]. Lancet. 2012;380(9859):2197-223.

3. Littleton SM, Cameron ID, Poustie SJ, Hughes DC, Robinson BJ, Neeman $T$, et al. The association of compensation on longer term health status for people with musculoskeletal injuries following road traffic crashes: emergency department inception cohort study. Injury. 2011;42(9):927-33.

4. Yang Z, Lowe AJ, de la Harpe DE, Richardson MD. Factors that predict poor outcomes in patients with traumatic vertebral body fractures. Injury. 2010;41(2):226-30.

5. Clay FJ, Newstead SV, Watson WL, Ozanne-Smith J, Guy J, McClure RJ. Biopsychosocial determinants of persistent pain 6 months after non-lifethreatening acute orthopaedic trauma. J Pain. 2010;11(5):420-30.

6. Mock C, Mackenzie E, Jurkovich G, Burgess A, Cushing B, deLateur B, et al. Determinants of disability after lower extremity fracture. J Trauma. 2000:49(6):1002-11.

7. Bosse MJ, MacKenzie EJ, Kellam JF, Burgess AR, Webb LX, Swiontkowski MF, et al. An analysis of outcomes of reconstruction or amputation of legthreatening injuries. N Engl J Med. 2002;347(24):1924-31.

8. Harris IA, Young JM, Dalaludin BB, Solomon MJ. The effect of compensation on general health in patients sustaining fractures in motor vehicle trauma. J Orthop Trauma. 2008;22(4):216-20.

9. Gabbe B, Cameron P, Williamson O, Edwards E, Graves S, Richardson M. The relationship between compensable status and long-term patient outcomes following orthopaedic trauma. Med J Aust. 2007;187(1):14-7.

10. Spearing NM, Connelly LB, Gargett S, Sterling M. Does injury compensation lead to worse health after whiplash? A systematic review. [Review]. Pain 2012;153(6):1274-82

11. Spearing NM, Connelly LB. Is compensation "bad for health"? A systematic meta-review. [Review]. Injury. 2011:42(1):15-24.

12. Grimes DA, Schulz KF. Bias and causal associations in observational research. Lancet. 2002;359(9302):248-52.

13. Atlas SJ, Tosteson TD, Blood EA, Skinner JS, Pransky GS, Weinstein JN. The impact of workers' compensation on outcomes of surgical and nonoperative therapy for patients with a lumbar disc herniation: SPORT. Spine (Phila Pa 1976). 2010;35(1):89-97.

14. Elbers NA, Hulst L, Cuijpers P, Akkermans AJ, Bruinvels DJ. Do compensation processes impair mental health? A meta-analysis. [Review]. Injury. 2013;44(5): 674-83.

15. Grant GM, O'Donnell ML, Spittal MJ, Creamer M, Studdert DM. Relationship between stressfulness of claiming for injury compensation and long-term recovery: a prospective cohort study. JAMA Psychiat. 2014;71(4):446-53.

16. Carroll LJ, Connelly LB, Spearing NM, Cote P, Buitenhuis J, Kenardy J. Complexities in understanding the role of compensation-related factors on recovery from whiplash-associated disorders: discussion paper 2. Spine (Phila Pa 1976). 2011;36(25 Suppl):S316-21. 
17. Clay F, Berecki-Gisolf J, Collie A. How well do we report on compensation systems in studies of return to work: a systematic review. J Occup Rehabil. 2014;24(1):111-24.

18. Safe Work Australia. Work-related injuries in Australia: Who did and didn't receive workers' compensation in 2009-10. Canberra: Safe Work Australia; 2011. Available from: http://www.safeworkaustralia.gov.au/sites/SWA/about/ Publications/Documents/644/Who\%20did\%20and\%20did\%20not\%20receive\% 20workers\%20compensation\%202009-10.pdf. Accessed 1 March 2017.

19. Australian Bureau of Statistics. 6324.0 - Work-Related Injuries, Australia, Jul 2013 to Jun 2014. Canberra: Australian Bureau of Statistics; 2014. Available from: http://www.abs.gov.au/ausstats/abs@.nsf/mf/6324.0. Accessed 1 March 2017.

20. Sterling M, Hendrikz J, Kenardy J. Compensation claim lodgement and health outcome developmental trajectories following whiplash injury: a prospective study. Pain. 2010;150(1):22-8.

21. Kilgour E, Kosny A, McKenzie D, Collie A. Interactions between injured workers and insurers in workers' compensation systems: a systematic review of qualitative research literature. J Occup Rehabil. 2015;25(1):160-81.

22. Kilgour E, Kosny A, McKenzie D, Collie A. Healing or harming? Healthcare provider interactions with injured workers and insurers in workers compensation systems. J Occup Rehabil. 2015;25(1):220-39.

23. Murgatroyd DF, Cameron ID, Harris IA. Understanding the effect of compensation on recovery from severe motor vehicle crash injuries: a qualitative study. Inj Prev. 2011;17(4):222-7.

24. Gabbe BJ, Sleney JS, Gosling CM, Wilson K, Sutherland A, Hart M, et al. Financial and employment impacts of serious injury: a qualitative study. Injury. 2014;45(9):1445-51.

25. Bagley S, White $H$, Golomb B. Logistic regression in the medical literature: standards for use and reporting, with particular attention to one medical domain. J Clin Epidemiol. 2001;54:979-85.

26. Harris IA, Young JM, Rae H, Jalaludin BB, Solomon MJ. Predictors of general health after major trauma. J Trauma Inj Infect Crit Care. 2008;64(4):969-74.

27. Murgatroyd DF, Harris IA, Tran Y, Cameron ID. The association between seeking financial compensation and injury recovery following motor vehicle related orthopaedic trauma. BMC Musculoskelet Disord. 2016;17:282

28. Murgatroyd DF, Harris IA, Tran Y, Cameron ID. Predictors of return to work following motor vehicle related orthopaedic trauma. BMC Musculoskelet Disord. 2016;17(1):1-13.

29. MacKenzie EJ, Bosse MJ, Pollak AN, Webb LX, Swiontkowski MF, Kellam JF, et al. Long-term persistence of disability following severe lower-limb trauma. Results of a seven-year follow-up. J Bone Joint Surg Am. 2005;87(8):1801-9.

30. Holbrook TL, Hoyt DB, Stein MB, Sieber WJ. Perceived threat to life predicts posttraumatic stress disorder after major trauma: risk factors and functional outcome. J Trauma Inj Infect Crit Care. 2001;51(2):287-92. discussion 92-3.

31. State Insurance Regulatory Authority, NSW. Guide for people injured in a motor vehicle accident. Available from: http://www.sira.nsw.gov.au/resourceslibrary/motor-accident-resources/publications/injury-advice-centre/guide-forpeople-injured-in-a-motor-vehicle-accident/nocache. Accessed 1 March 2017.

32. State Insurance Regulatory Authority, NSW. Workers Compensation. Available from: http:/www.sira.nsw.gov.au/workers-compensation. Accessed 1 March 2017.

33. Association for the Advancement of Automotive Medicine. The Abbreviated Injury Scale, 1990 Revision, Update 98. Barrington, Illinois: Association for the Advancement of Automotive Medicine; 1998.

34. Baker SP, O'Neill B, Haddon Jr W, Long WB. The injury severity score: a method for describing patients with multiple injuries and evaluating emergency care. J Trauma. 1974;14(3):187-96.

35. Stevenson M, Segui-Gomez M, Lescohier I, Di Scala C, McDonald-Smith G. An overview of the injury severity score and the new injury severity score. Inj Prev. 2001;7(1):10-3.

36. Australian Bureau of Statistics. Australian Standard Classification of Occupations (ASCO), Cat.no. 1220.0: Australian Bureau of Statistics; 1997. Available from: http://www.abs.gov.au/ausstats/abs@.nsf/66ł306f503e529a5ca25697e0017661f/ 5c244fd9d252cfc8ca25697e00184d35!OpenDocument. Accessed 1 March 2017.

37. Australian Bureau of Statistics. 4363.0.55.001 - Australian Health Survey: Users' Guide, 2011-13. Canberra: Australian Bureau of Statistics. Available from: http://www.abs.gov.au/AUSSTATS/abs@.nsf/Lookup/4363.0.55. 001Glossary12011-13?OpenDocument. Accessed 1 March 2017.

38. Australian Bureau of Statistics. Technical Paper Census of Population and Housing: Socio-Economic Indexes for Area's (SEIFA), Cat no. 2039.0.55.001: Australian Bureau of Statistics; 2001. Available from: http://www.abs.gov.au/ AUSSTATS/abs@.nsf/DetailsPage/2039.0.55.0012001?OpenDocument. Accessed 1 March 2017.
39. Australian Bureau of Statistics. National Health Survey: Users' Guide - Electronic Publication, Cat.no. 4363.0.55.001: Australian Bureau of Statistics; 2004-05. Available from: http://www.abs.gov.au/ausstats/abs@.nsf/ProductsbyReleaseDate/ E88508137A2912FECA25762E0017C550?OpenDocument. Accessed 1 March 2017.

40. Australian Institute of Health and Welfare. National Health Priority Areas. Available from: http://www.aihw.gov.au/national-health-priority-areas/. Accessed 1 March 2017

41. Australian Bureau of Statistics. National Health Survey: Summary of Results, Cat. No. 4364.0: Australian Bureau of Statistics; 2004-05. Available from: http://www.abs.gov.au/AUSSTATS/abs@.nsf/DetailsPage/4364.0200405? OpenDocument. Accessed 1 March 2017.

42. Foreman P, Murphy G, Swerissen H. Barriers and facilitators to return to work: A literature review. Melbourne: Australian Institute for Primary Care, La Trobe University; 2006. Available from: http://www.tavrp.com/wp-content/ uploads/2014/07/LaTrobeRTWReview0706.pdf. Accessed 1 March 2017.

43. Cole DC, Mondloch MV, Hogg-Johnson S, Early Claimant Cohort Prognostic Modelling G. Listening to injured workers: how recovery expectations predict outcomes-a prospective study. Can Med Assoc J. 2002;166(6):749-54.

44. Mondloch MV, Cole DC, Frank JW. Does how you do depend on how you think you'll do? A systematic review of the evidence for a relation between patients' recovery expectations and health outcomes. [erratum appears in CMAJ 2001 Nov 13;165(10):1303]. Can Med Assoc J. 2001;165(2):174-9.

45. Babor TF, Higgins-Biddle JC, Saunders JB, Monteiro MG. The Alcohol Use Disorders Identification Test, Guidelines Use in Primary Care, Second Edition: Department of Mental Health and Substance Dependence, World Health Organization; 2001. Available from: http://apps.who.int/iris/bitstream/10665/ 67205/1/WHO_MSD_MSB_01.6a.pdf. Accessed 1 March 2017.

46. Bush K, Kivlahan D, McDonell M, Fihn S, Bradley K. The AUDIT alcohol consumption questions (AUDIT-C): an effective brief screening test for problem drinking. Ambulatory Care Quality Improvement Project (ACQUIP). Alcohol use disorders identification test. Arch Intern Med. 1998;158(16): 1789-95.

47. National Health and Medical Research Council. Australian Alcohol Guidelines, Health Risks and Benefits: National Health and Medical Research Council, Commonwealth of Australia. 2001. Available from: https://www. nhmrc.gov.au/guidelines-publications/ds9. Accessed 1 March 2017.

48. University of Sydney. The Drink-less program, Alcohol Use Disorders Identification Test (AUDIT): University of Sydney. Available from: http://sydney. edu.au/medicine/addiction/drinkless/resources.php. Accessed 1 March 2017.

49. Making a claim, Information you need to know when making a claim if you have been injured in a car crash. State Insurance Regulatory Authority, NSW; 2017. Available from: http://www.sira.nsw.gov.au/motor-accidents/making-aclaim. Accessed 1 March 2017.

50. Hosmer DW, Lemeshow S. Applied logistic regression. 2nd ed. New York: John Wiley \& Sons; 2000

51. Cameron AJ, Magliano DJ, Dunstan DW, Zimmet PZ, Hesketh K, Peeters A, et al. A bi-directional relationship between obesity and health-related quality of life: evidence from the longitudinal AusDiab study. Int J Obes. 2012;36(2):295-303.

52. Wong E, Stevenson C, Backholer K, Mannan H, Pasupathi K, Hodge A, et al. Adiposity measures as predictors of long-term physical disability. Ann Epidemiol. 2012;22(10):710-6.

53. Wright L, Schur E, Noonan C, Ahumada S, Buchwald D, Afari N. Chronic pain, overweight, and obesity: findings from a community-based twin registry. J Pain. 2010;11(7):628-35.

54. Ostbye T, Dement JM, Krause KM. Obesity and workers' compensation: results from the Duke Health and Safety Surveillance System. Arch Intern Med. 2007;167(8):766-73.

55. Finkelstein EA, DiBonaventura M, Burgess SM, Hale BC. The costs of obesity in the workplace. J Occup Environ Med. 2010;52(10):971-6.

56. Trogdon JG, Finkelstein EA, Hylands T, Dellea PS, Kamal-Bahl SJ. Indirect costs of obesity: a review of the current literature. Obes Rev. 2008;9(5):489-500.

57. Johnston $\mathrm{P}$, Brooks $\mathrm{C}$, Savage $\mathrm{H}$. Fatal and serious road crashes involving motorcyclists Canberra: Road Safety, Infrastructure and Surface Transport Policy, Department of Infrastructure, Transport, Regional Development and Local Government. 2008. Available from: https://infrastructure.gov.au/roads/ safety/publications/2008/pdf/mono20.pdf. Accessed 1 March 2017.

58. Wilson SJ, Begg DJ, Samaranayaka A. Validity of using linked hospital and police traffic crash records to analyse motorcycle injury crash characteristics. Accid Anal Prev. 2012;49:30-5. 
59. Lujic S, Finch C, Boufous S, Hayen A, Dunsmuir W. How comparable are road traffic crash cases in hospital admissions data and police records? An examination of data linkage rates. Aust N Z J Public Health. 2008;32(1):28-33.

60. Australian guidelines to reduce health risks from drinking alcohol. Canberra: National Health and Medical Research Council; 2009. Available from: http:// www.nhmrc.gov.au/_files_nhmrc/publications/attachments/ds10-alcohol. pdf. Accessed 1 March 2017.

61. National Preventative Health Taskforce. Technical Report No 3: Preventing alcohol-related harm in Australia: a window of opportunity. Prepared for the National Preventative Health Taskforce by the Alcohol Working Group. 2008. Available from: http://www.health.gov.au/internet/preventativehealth/ publishing.nsf/Content/tech-alcohol-toc. Accessed 1 March 2017.

62. Australian Institute of Health and Welfare 2010. Australia's health 2010 Australia's health series no. 12. Cat. no. AUS 122. Canberra: Australian Institute of Health and Welfare; 2010. Available from: http://www.aihw.gov. au/WorkArea/DownloadAsset.aspx?id=6442452962. Accessed 1 March 2017.

63. Australian Bureau of Statistics. 4228.0 - Adult Literacy and Life Skills Survey, Summary Results, Australia, 2006 (Reissue). Canberra: Australian Bureau of Statistics; 2008. Available from: http://www.abs.gov.au/AUSSTATS/abs@.nsf/ Previousproducts/4228

OMain\%20Features22006\%20\%28Reissue\%29? opendocument\&tabname= Summary\&prodno $=4228.0 \&$ issue $=2006 \% 20 \% 28$ Reissue $\% 29 \&$ num $=\& v i e w$. Accessed 1 March 2017.

64. Sullivan M, Adams H, Horan S, Maher D, Boland D, Gross R. The role of perceived injustice in the experience of chronic pain and disability: scale development and validation. J Occup Rehabil. 2008;18(2):249-61.

65. Thompson J, O'Donnell M, Stafford L, Nordfjaern T, Berk M. Association between attributions of responsibility for motor vehicle crashes, depressive symptoms, and return to work. Rehabil Psychol. 2014;59(4):376-85.

66. Prang K-H, Newnam S, Berecki-Gisolf J. The impact of family and workrelated social support on musculoskeletal injury outcomes: a systematic review. J Occup Rehabil. 2015;25(1):207-19.

67. Karasek R, Brisson C, Kawakami N, Houtman I, Bongers P, Amick B. The Job Content Questionnaire (JCQ): an instrument for internationally comparative assessments of psychosocial job characteristics. J Occup Health Psychol. 1998;3(4):322-55.

68. Broadbent E, Petrie KJ, Main J, Weinman J. The brief illness perception questionnaire. J Psychosom Res. 2006;60(6):631-7.

\section{Submit your next manuscript to BioMed Central and we will help you at every step:}

- We accept pre-submission inquiries

- Our selector tool helps you to find the most relevant journal

- We provide round the clock customer support

- Convenient online submission

- Thorough peer review

- Inclusion in PubMed and all major indexing services

- Maximum visibility for your research

Submit your manuscript at www.biomedcentral.com/submit

) Biomed Central 